\title{
“El” Organ adıyla kurulmuş Türk ve Gürcü deyimlerinde eşdeğerlikler
}

\section{Tamar TOLORAIA ${ }^{1}$}

\begin{abstract}
APA: Toloraia, T. (2020). "El” Organ adıyla kurulmuş Türk ve Gürcü deyimlerinde eşdeğerlikler. RumeliDE Dil ve Edebiyat Araşttrmaları Dergisi, (18), 512-519. DOI: 10.2900o/rumelide.706244.
\end{abstract}

\section{$\ddot{O} \mathbf{z}$}

Sabit kelime birleşimleri olan deyimler, dilin en önemli unsurlarından biridir ve dil birimleri arasında yer almaktadır. Toplumların yaşayış biçimlerini, algı ve davranışlarını yansıtan deyimlerin incelemesi Türk ve Gürcü milletlerinin kültürel benzerliklerini ortaya çıkarmak için büyük önem taşımaktadır. Türkler ve Gürcüler asırlar boyunca komşuluk ilişkisi içerisinde olmuşlardır. Bundan dolayı kültürel anlamda pek çok benzerlikler ortaya çıkmıştır. Bu benzerliklerin belirlenmesi adına başvurulabilecek önemli kaynaklardan biri de iki dilde eş değerlik gösteren deyimlerin tespit edilmesidir. Dilin temel varlığını oluşturan unsurlarından olan organ adlarının deyimler içerisinde oldukça geniş bir yeri vardır. Bu çalışmada E. Mamulia'nın hazırlamış olduğu Türkçe-Gürcüce Deyimler Sözlüğü ve TDK’nin Atasözleri ve Deyimler Sözlüğü’nde geçen el organ adıyla kurulmuş deyimler temel alınmış ve eşdeğerlilik bakımından değerlendirilmiştir. Çalışma dört bölümden oluşmaktadır. Birinci bölümde her iki dilde birebir benzeyen, aynı sözcüklerle yapılmış ve aynı anlama gelen deyimler listelenmiştir. İkinci bölümde anlamca benzeyen ancak içerdiği kelimelerin bir kısmı farklı olan deyimler listelenmiştir. Üçüncü bölümde her iki dilde farklı kelimelerle yapılmış ancak aynı anlamları taşıyan deyimlere yer verilmiştir. Dördüncü bölümde ise kelime seçimi bakımından aynı ancak anlam bakımından farklı olan deyimler listelenmiş ve iki dildeki anlamları verilmiştir.

Anahtar kelimeler: Deyim, Türkçe, Gürcüce, eşdeğerlik.

\section{Equivalencies in Turkish and Georgian idioms established by the name of "hand"}

\begin{abstract}
Phrases, which are fixed word combinations, are one of the most important elements of language and are among the language units. The analysis of idioms that reflect the societies' living styles, perceptions and behaviors has a great importance to reveal the cultural similarities of the Turkish and Georgian nations. Turks and Georgians have been in a neighborhood relationship for centuries. Therefore, many cultural similarities have emerged. One of the important sources that can be used for the determination of these similarities is the identification of idioms that are equivalent in two languages. Names of organs, which constitute the basic existence of language, have a very wide place in idioms. In this study, the expressions established by E. Mamulia in the Turkish-Georgian Idioms Dictionary and the Proverbs and İdioms Dictionary of TDK are based on and evaluated in terms of equivalence. The study consists of four parts. In the first part, the idioms which are identical in both languages, made with the same words and have the same meaning are listed. In the second part, idioms that are similar in meaning but have some difference with some of words they contain are listed. In the third part are given idioms, which are made with different words in both languages but
\end{abstract}

1 YL Öğrencisi, Selçuk Üniversitesi, Sosyal Bilimler Enstitüsü, Türk Dili ve Edebiyatı ABD (Konya, Türkiye), tam.toloraia@gmail.com, ORCID ID: 0000-0002-4433-0517 [Makale kayıt tarihi: 11.12.2019-kabul tarihi: 20.03.2020; DOI: $10.29000 /$ rumelide.706244] 
having the same meanings. In the fourth part, idioms which are the same in terms of word selection but have different in meanings in two languages are listed and their meanings are given.

Keywords: Idiom, Turkish, Georgian, equivalence.

\section{Giriş}

Deyimler bir dilin anlatım zenginliğidir ve günlük hayatımızda sıkça kullanılmaktadır. Her toplumun kendi kültürüne özgü deyimleri vardır. Deyim kelimesi, birçok dilbilimci tarafından çeşitli şekilde yorumlanmıştır.

Güncel Türkçe Sözlük’te deyim sözcügü, "Genellikle gerçek anlamından az çok ayrı, kendine özgü bir anlam taşıyan kalıplaşmış söz öbeği, tabir” olarak açıklanmaktadır.

Türkiye'de deyimler üzerine yaptığı çalışmalarla tanınan Ö. A. Aksoy ise deyim için şu tanımı vermektedir: "Çekici bir anlatım kılığı taşıyan ve çoğunun gerçek anlamından ayrı bir anlamı bulunan kalıplaşmış sözcük toplulukları” (Aksoy, 1984: 49).

Z. Korkmaz, Gramer Terimleri Sözlüğü’nde deyim kelimesini "Gerçek anlamından farklı bir anlam taşıyan ve çekici bir anlatım özelliğine sahip olan kelime öbeği” şeklinde tanımlamıştır (Korkmaz, 1992: 43).

B. Vardar'ın hazırlamış olduğu Açıklamalı Dilbilim Terimleri Sözlüğü adlı eserde deyim kelimesi “Bir tür sözlüksel birim oluşturan anlambirim toplaşması; genellikle öz anlamından az çok ayrı bir anlam içeren kalıplaşmış söz” olarak tanımlanmaktadır (Vardar, 2002: 71).

Deyimler konusu ile ilgili çalışma yapan Gürcü dilbilimci A. Oniani deyim için şu açıklamayı yapmıştır "Sözcük birleşim biçimi olan, çözülmeyen, sağlam sözcüksel birimidir ve onu oluşturan sözcüklerin anlamlarından elde edilemez” (Oniani, 1966: 7). Ayrıca G. M. Öztürk ise şöyle belirtmektedir “Her dilin kültüründe var olan anlatım biçimi vardır. Bu anlatım biçimlerini aktarmak zannedildiği kadar kolay olmayan bir iştir. Özellikle de deyimleri çevirmek çok çetin bir iştir (Öztürk, 2019: 1633).

Deyimler konusunu ele alan bir diğer Gürcü dilbilimci A. Taqaişvili’ye göre deyimler, anlamlılık işlevi olan sözcüksel birleşim biçimi ve semantik açısından çözülmeyen birimlerdir (Taqaişvili, 1961: 9).

Alıntı yaptığımız her iki dildeki kaynaklardan da anlaşılacağı üzere deyimler, genel kural niteliği taşımayan kalıplaşmış sözcüklerdir. Konu ile ilgili araştırmaları olan K. Kenzhalin'e göre deyimlerin en belirgin özellikleri, deyim yapısını oluşturan unsurların anlamlarından farklı yeni bir anlamı aktarmalarıdır (Kenzhalin, 2017: 122). Böylece G.M. Öztürk'e göre Çevirmen erek dilin kültürüne hâkim değilse daha da zorlu hâle gelebilir. Bundan dolayı deyimleri çevirirken sözcüklerden yola çlkmaktan ziyade o dilin kültüründe deyimin nasıl kullanıldığını inceleyip araştırması gerekmektedir (Öztürk, 2019: 1633) şeklinde ifade etmektedir.

Deyimlerde halkların yaradılıştan gelen özelliklerini ve dünya görüşünü hissetmek ve görmek mümkündür (Tandilava ve Tsetskhladze, 2015: 104). Bu bakımdan Türk ve Gürcü milletlerinin kültürel benzerliklerini ortaya çıkarmak için ortak deyimlerin araştırılması büyük önem taşımaktadır. 
Deyimleri oluşturan sözcükler incelendiğinde uzuv isimleri barındıran deyimlerin sayısının oldukça çok olduğu anlaşılmaktadır. Uzuv isimleri ile oluşturulan deyimlere baktığımızda ise el organ adıyla kurulmuş deyimlerin sayısının fazlalığı dikkat çekmektedir. Gürcücede $e l$ kelimesiyle ilgili yüz elliye yakın deyim kaydedilmiştir. Bunlardan bir kısmı Türkiye Türkçesinde de aynen kullanılmaktadır, bir kısmının ise Türkiye Türkçesinde karşllı̆̆ bulunamamıştır. Bu çalışmada, Türkiye Türkçesinde ve Gürcücede el organ adıyla kurulmuş deyimlerin mukayesesi yapılmıştır.

Deyimlerle ilgili yapılan karşılaştırmalı çalışma ve araştırmaların birçoğunda farklı dillerin deyimlerinde ortaya çıkan eşdeğerlikler incelenmiştir. Türkçe ve Gürcüce gibi farklı dil ailelerine mensup olan dillerde genellikle üç eşdeğerlilik grubu ortaya çıkmaktadır. Bunlar, tam, kısmî ve sıfır eşdeğerlilik gruplarıdır. Söz konusu gruplara girecek deyimler listelenirken A. Aktaş’ın "Karşılaştırmalı Dilbilim Açısından Türkçe ve Almanca Deyimlerde Kadın” makalesindeki tam eşdeğerlik, kısmi ve sıfır eşdeğerlik tanımları dikkate alınmıştır. Bu çalışmanın bölümleri oluşturulurken A. B. Şahin’in "Hayvan İsimleri ile Kurulmuş Türk ve Gürcü Atasözlerinde Eşdeğerlikler” adlı makalesinden yararlanılmış ve ek olarak kelime seçimi bakımından aynı ve anlam bakımından farklı olan deyimler bölümü eklenmiştir. G. M. Öztürk'ün, "Kültür Aktarımında Çeviri Stratejileri: Mikheil Cavahişvili’nin "Çançura" Adlı Öyküsünün Türkçe Çevirisindeki Deyimlerin Karşılaştırmalı Analizi” adlı çalışmasında deyimlerin çevirisi ile ilgili olarak N. Tsetskhladze'nin "Çeviri süreci zor ve sorumluluk işi ve birçok nüans göz önünde bulundurulmalıdır. Deyimleri oluşturan metinler çevirmen için özgün gerçekliği sunar. Doğrudan, kelimesi kelimesine çeviri verilen içeriği değiştirebilir” ifadesine vurgu yapılmıştır (akt. Öztürk, 2019: 1632). Bu tespitten yola çıkarak, çalışmamızın "Kelime Seçimi bakımından aynı ve anlam bakımından farklı olan deyimler" bölümünde listelenen deyimlerin doğrudan (kelimesi kelimesine) çevirisinin dışında söz konusu deyimlerin anlamları da ayrı bir sütünde verilmiştir.

\section{A) “El” organ adı geçen Türk ve Gürcü deyimlerinde tam eşdeğerlik}

A. Aktaş, deyimlerde ortaya çıkan tam eşdeğerlik için "her iki dilde de hem yapısal açıdan hem de anlamsal açıdan birbirine benzemektedirler" ifadesini kullanmıştır (Aktaş 2008: 8). Bu başlık altında verilen örnekler tam eşdeğerlik ölçütlerine göre listelenmiştir. Yani bu bölümde her iki dilde aynı sözcüklerle yapılmış ve aynı anlama gelen deyimlere yer verilmiştir.

\begin{tabular}{|c|c|c|c|}
\hline & $\begin{array}{l}\text { Türkiye } \\
\text { Deyimler }\end{array}$ & Gürcüce Deyimler & $\begin{array}{l}\text { Gürcüceden Direkt } \\
\text { Çeviri }\end{array}$ \\
\hline 1. & El açmak & Khelis gaşla (Mamulia, 2006: 104) & El açmak \\
\hline 2. & El ele vermek & Kheli Khels mistses (Mamulia, 2006: 105) & El ele vermek \\
\hline 3. & El kaldırmak & Khelis aghmartva (Mamulia, 2006: 115) & El kaldırmak \\
\hline 4. & El katmak & Khelis şeşveleba (Mamulia, 2006: 115) & El katmak \\
\hline 5. & El vermek & Khelis gamartva(Mamulia, 2006: 116) & El vermek \\
\hline 6. & Elde tutmak & Khelşi datzera (Mamulia, 2006: 105) & Elde tutmak \\
\hline 7. & $\begin{array}{l}\text { Elden ayaktan düşmek } \\
\text { (kesilmek) }\end{array}$ & Khel-pekhi tsaertva (Mamulia, 2006: 105) & Eli ayağ kesilmek \\
\hline 8. & $\begin{array}{l}\text { Elden ele dolaşmak } \\
\text { (gezmek) }\end{array}$ & Khelidan khelşi gadasvla (Mamulia, 2006: 106) & Elden ele geçmek \\
\hline 9. & Elden kaçmak & Khelidan daskhlet'va (Mamulia, 2006: 112) & Elden kaymak \\
\hline 10. & Ele alınmaz & Khelşi ar aigeba (Mamulia, 2006: 106) & Ele alınmaz \\
\hline
\end{tabular}




\begin{tabular}{|c|c|c|c|}
\hline 11. & Ele almak & $\begin{array}{l}\text { Khelis mokideba (sakmes) (Mamulia, } \\
\text { 2006: 106) }\end{array}$ & (işi) Ele almak \\
\hline 12. & Ele geçirmek & Khelşi çagdeba(Mamulia, 2006: 113) & Ele geçirmek \\
\hline 13. & 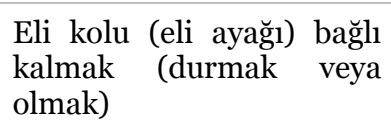 & Khel-pekh şek'ruli qopna (Mamulia, 2006: 107) & Eli ayağı bağlı olmak \\
\hline 14. & $\begin{array}{l}\text { Eli ayağı buz kesilmek } \\
\text { (tutmamak) }\end{array}$ & $\begin{array}{l}\text { Khel-pekhis ts'artmeva (Mamulia, 2006: } \\
\text { 107) }\end{array}$ & Eli ayağı tutamamak \\
\hline 15 & $\begin{array}{l}\text { Eli ayağı çözülmek } \\
\text { (gevşemek) }\end{array}$ & $\begin{array}{l}\text { Khel-pekhis moduneba (Mamulia, 2006: } \\
\text { 107) }\end{array}$ & Eli ayağı gevşemek \\
\hline 16. & Eli ayağı titremek & Khel-pekhis kankali (Mamulia, 2006: 108) & Eli ayağ titremek \\
\hline 17. & Eli boş gelmek & Kheltsarieli mosvla (Mamulia, 2006: 108) & Eli boş gelmek \\
\hline 18. & Eli dar (darda)olmak & Khelmotçerili kopna (Mamulia, 2006: 109) & Eli sıkı olmak \\
\hline 19. & Eli genişlemek & Khelis momartva (Mamulia, 2006: 114) & Eli genişlemek \\
\hline 20. & (bir işe) Eli yatmak & Khelis gatzapva (Mamulia, 2006: 109) & Eli yatmak \\
\hline 21. & Eli olmak (bir işte) & Misi kheli urevia (Mamulia, 2006: 110) & Eli var (bir işte) \\
\hline 22. & Elinde kalmak & Khelşi şerçena (Mamulia, 2006: 111) & Elinde kalmak \\
\hline 23. & $\begin{array}{l}\text { Elinden bir iş (şey) } \\
\text { gelmemek }\end{array}$ & $\begin{array}{l}\text { Khelidan araperi gamosdis (Mamulia, } \\
\text { 2006: 111) }\end{array}$ & $\begin{array}{l}\text { Elinden bir şey } \\
\text { gelmez }\end{array}$ \\
\hline 24. & Eline almak & Khelşi agheba (Mamulia, 2006: 112) & Eline almak \\
\hline 25. & Eline bakmak(birinin) & Khelebşi tskera (Mamulia, 2006: 112) & Ellerine bakmak \\
\hline 26. & Eline geçirmek & Khelşi çagdeba (Mamulia, 2006: 115) & Eline geçirmek \\
\hline 27. & $\begin{array}{l}\text { (bir yerden, bir şeyden) } \\
\text { Elini } \\
\text { ayağını (eteğini) kesmek } \\
\text { (çekmek) }\end{array}$ & $\begin{array}{l}\text { Khel-pekhis amokveta (Mamulia, 2006: } \\
\text { 114) }\end{array}$ & Elini ayağını kesmek \\
\hline 28. & Elini çabuk tutmak & Marcve khelis kona (Mamulia, 2006: 108) & Eli çabuk olmak \\
\hline 29. & $\begin{array}{l}\text { Eli cebine (cüzdanına veya } \\
\text { kesesine) } \\
\text { (varmamak) }\end{array}$ & $\begin{array}{l}\text { Cibeze khelis ar gak'vra (Mamulia, 2006: } \\
\text { 114) }\end{array}$ & Eli cebine gitmemek \\
\hline 30. & $\begin{array}{l}\text { Elini kana bulamak } \\
\text { (bulaştırmak) }\end{array}$ & $\begin{array}{l}\text { Khelebis siskhlşi gasvra (Mamulia, 2006: } \\
\text { 115) }\end{array}$ & $\begin{array}{l}\text { Ellerini kanla } \\
\text { kirletmek, bulamak }\end{array}$ \\
\hline 31. & $\begin{array}{l}\text { Elini kolunu bağlamak } \\
\text { (birinin) }\end{array}$ & Khelebis şeboçva (Mamulia, 2006: 115) & Ellerini bağlamak \\
\hline 32. & Elini sürmemek (bir şeye) & Khelis ar mokhleba (Mamulia, 2006: 116) & Elini sürmemek \\
\hline 33. & Elini uzatmak & Khelis gatsodeba (Mamulia, 2006: 116) & Elini uzatmak \\
\hline
\end{tabular}

\section{B) “El” organ adı geçen Türk ve Gürcü deyimlerinde kısmî eşdeğerlik}

Çalışmanın bu bölümünde en az bir kelimesi ortak ve anlam bakımından aynı olan, "el" organ adıyla kurulmuş Türkçe ve Gürcüce deyimler yer almaktadır. Deyimler listelenirken A. Aktaş'ın "Karşılaştırmalı Dilbilim Açısından Türkçe ve Almanca Deyimlerde Kadın" isimli makalesinde yer alan kısmî eşdeğerlik tanımı dikkate alınmıştır. Aktaş, kısmî eşdeğerlik grubuna giren deyimlerdeki 
kelimelerin en az birinin diğer deyimde de bulunması ve örtüşmesi gerektiğini ifade etmiştir (Aktaş 2008: 8).

\begin{tabular}{|c|c|c|c|}
\hline & $\begin{array}{l}\text { Türkiye } \quad \text { Türkçesi } \\
\text { Deyimler }\end{array}$ & Gürcüce Deyimler & $\begin{array}{l}\text { Gürcüceden } \\
\text { Direkt Çeviri }\end{array}$ \\
\hline 1. & (birinin) Eli ayağı olmak & Marcvena khelad gakhdoma (Mamulia, 2006: 107) & $\begin{array}{l}\text { (birinin) Sağ } \quad \text { eli } \\
\text { olmak }\end{array}$ \\
\hline 2. & Ayağının bağını çözmek & Khel-pekhis gakhsna (Mamulia, 2006: 45) & $\begin{array}{l}\text { Elini ve ayağını } \\
\text { çözmek }\end{array}$ \\
\hline 3. & El el üstünde oturmak & Gulkheldak'repili cdoma (Mamulia, 2006: 104) & Eli göğsünde oturmak \\
\hline 4. & El çekmek & Tavis danebeba (Mamulia, 2006: 114) & Baş çekmek \\
\hline 5. & $\begin{array}{l}\text { Elde avuçta (bir şey) } \\
\text { kalmamak }\end{array}$ & Kheltsarieli darçena (Mamulia, 2006: 105) & Eli boş kalmak \\
\hline 6. & Elden çıkarmak & Khelidan gaşveba (Mamulia, 2006: 106) & Elden bırakmak \\
\hline $7 \cdot$ & Ele avuca sığmamak & Khelidan skhlteba (Mamulia, 2006: 106) & Elden kaymak \\
\hline 8. & Eli armut devşirmek & Khel-pekh şekruli (Mamulia, 2006: 107) & Eli ayağı bağlı \\
\hline 9. & Eli ayağı tutmak & Mukhlebi ar emorçileba (Mamulia, 2006: 108) & Dizleri tutmamak \\
\hline 10. & Eli boş çıkmak & Khelis motsarva (Oniani, 1966: 191) & Eli boş kalmak \\
\hline 11. & Eli dursa ayağı durmaz & Misi gaçereba ar aris (Mamulia, 2006: 109) & Duracağı yok \\
\hline 12. & Eli ekmek tutmak & Puris puli akvs (Mamulia, 2006: 109) & Ekmek parası var \\
\hline 13. & Eli kalem tutmak & Kalami utzris (Mamulia, 2006: 109) & Kalemi keskin olmak \\
\hline 14. & Eli varmamak (gitmemek) & Guli ar miudis (Mamulia, 2006: 110) & Kalbi gitmemek \\
\hline 15 & $\begin{array}{l}\text { Elinden hiçbir şey } \\
\text { kurtulmamak }\end{array}$ & Khelidan kvelaperi gamosdis (Mamulia, 2006: 111) & $\begin{array}{l}\text { Elinden her şey } \\
\text { çlkmak }\end{array}$ \\
\hline 16. & $\begin{array}{l}\text { Eline ayağına düşmek } \\
\text { (sarılmak, kapanmak) }\end{array}$ & Pekhebşi uvardeba (Mamulia, 2006: 112) & Ayaklarına düşmek \\
\hline 17. & Eline eteğine sarılmak & $\begin{array}{l}\text { Khel-pekhis dakotsvna } \\
\text { (Mamulia, 2006: 113) }\end{array}$ & $\begin{array}{l}\text { Elini ayağını } \\
\text { öpmek }\end{array}$ \\
\hline 18. & Eline geçmek & Khelşi çavardna (Mamulia, 2006:113 ) & Eline düşmek \\
\hline 19. & $\begin{array}{l}\text { Eline su dökemez } \\
\text { (birinin) }\end{array}$ & Khelebs ulok'avs (Mamulia, 2006: 114) & Elini yalamak \\
\hline 20. & $\begin{array}{l}\text { Elini kolunu sallaya } \\
\text { sallaya gelmek }\end{array}$ & Kheltsarieli dabruneba (Mamulia, 2006: 115) & Eli boş dönmek \\
\hline 21. & $\begin{array}{l}\text { Elini kolunu sallaya } \\
\text { sallaya gezmek }\end{array}$ & Udardelad siaruli (Mamulia, 2006: 115) & $\begin{array}{l}\text { Dertsiz dolaşmak } \\
\text { (gezmek) }\end{array}$ \\
\hline 22. & $\begin{array}{l}\text { Elini sıcak sudan soğuk } \\
\text { suya sokmamak }\end{array}$ & Khelis ar gandzreva (Mamulia, 2006: 115) & $\begin{array}{l}\text { Elini } \\
\text { kıpırdatmamak }\end{array}$ \\
\hline 23. & Elini vicdanına koymak & Gulze khelis dadeba (Mamulia, 2006: 116) & $\begin{array}{l}\text { Elini kalbine } \\
\text { koymak }\end{array}$ \\
\hline 24. & $\begin{array}{l}\text { İnsan eli değmemiş (veya } \\
\text { dokunmamış) }\end{array}$ & Khelukhlebeli (Mamulia, 2006: 104) & El değmemiş \\
\hline
\end{tabular}




\section{C) “El” organ adı geçen Türk ve Gürcü deyimlerinde sıfır eşdeğerlik}

$\mathrm{Bu}$ eşdeğerlilik modelinde deyimlerin başka bir dile aktarılmasında sadece deyimin anlamı diğer dile aktarılıyor, fakat hiçbir şekilde erek dilde bir benzerlik gözlenmemektedir (Aktaş, 2008: 9). Bu tanımdan yola çıkarak makalenin bu kısmında kelime seçimi bakımından farklı ve anlam bakımından aynı olan deyimlere yer verilmiştir. Söz konusu deyimlerin listelenmesinde, Türkiye Türkçesinde "el" organ adıyla kurulmuş deyimler temel alınmıştır.

\begin{tabular}{|l|l|l|l|}
\hline & $\begin{array}{l}\text { Türkiye Türkçesi } \\
\text { Deyimler }\end{array}$ & Gürcüce Deyimler & $\begin{array}{l}\text { Gürcüceden } \\
\text { Direkt Çeviri }\end{array}$ \\
\hline $\mathbf{1 .}$ & $\begin{array}{l}\text { (bir yerden, bir şeyden) } \\
\text { Elini ayağını kesmek } \\
\text { (çekmek) }\end{array}$ & Tavis danebeba (Mamulia, 2006: 114) & Başını bırakmak \\
\hline $\mathbf{2 .}$ & El etek öpmek & Pekhebşi çavardna (Mamulia, 2006: 105) & Ayaklarına düşmek \\
\hline 3. & El üstünde tutmak & Khelisgulze dasma (Mamulia, 2006: 116) & Avucunda oturtmak \\
\hline 4. & Eli bol & Savse cibis kona (Mamulia, 2006: 108) & Cebi dolu olmak \\
\hline 5. & Elinden geleni yapmak & Tavis ar dazogva (Mamula, 2006: 111) & Kendine kıymak \\
\hline 6. & Elinden iş çıkmamak & Moukherkhebeli (Mamulia, 2006: 112) & Beceriksiz olma \\
\hline 7. & Elinden kurtulmak & Tavis daghtzeva (Mamulia, 2006: 112) & Başını kurtarmak \\
\hline 8. & Eline doğmak & Tvaltzin gazrda (Mamulia, 2006: 111) & $\begin{array}{l}\text { Gözünün } \\
\text { büyümek }\end{array}$ \\
\hline 9. & Elle tutulününde \\
\hline
\end{tabular}

\section{D) Kelime seçimi bakımından aynı ve anlam bakımından farklı olan deyimler}

Deyim sözlükleri taranırken kelime tercihi bakımından aynı ancak anlam olarak çok farklı olan deyimlere rastlanmıştır. Sayıları az olsa da bu deyimler ayrı bir başlık altında incelenmiştir. Söz konusu deyimler, yalancı eşdeğerlik grubuna giren deyimler olarak değerlendirilmiştir. Eşdeğerlik konusu üzerine çalışmaları olan M. Uğurlu'ya göre yalancı eş değerlik, "kaynak anlaşma birliğindeki bir kelimenin, ses ve yapı veya sadece ses bakımından aynı olan veya lehçeler arasındaki düzenli ses denklikleriyle aynı kaynaktan geldiği kolayca bilinen, yani benzer şeklinin, hedef lehçede bulunması; ancak bu iki kelimenin kavram alanlarının birbirine eş değer olmaması durumudur" (Uğurlu 2012: 218). Bazı yapılar eş değer gibi görünse de kavram alanları bakımından birbiriyle örtüşmez. Örneğin Türkiye Türkçesinde el değiştirmek deyimi "bir şeyin kullanımı veya mülkiyeti bir kimseden başka bir kimseye geçmek” anlamında kullanılmaktadır (https://sozluk.gov.tr/ 14.11.2019'da erişildi). Gürcücede ise khelis monatsvleba (el değiştirmek) deyimi "birinden yardım almak; Birinden borç para almak" manasindadır (Oniani, 1966: 189).

\begin{tabular}{|l|l|l|l|}
\hline $\begin{array}{l}\text { Türkiye } \\
\text { Türkçesi } \\
\text { Deyimler }\end{array}$ & $\begin{array}{l}\text { Deyimlerin Türkiye } \\
\text { Türkçesindeki Anlamları }\end{array}$ & $\begin{array}{l}\text { Gürcüce } \\
\text { Deyimler }\end{array}$ & $\begin{array}{l}\text { Deyimlerin Gürcücedeki } \\
\text { Anlamları }\end{array}$ \\
\hline El almak & $\begin{array}{l}\text { 1. Eskimiş tarikatlarda bir mürit, } \\
\text { mürşidinden, başkalarına yol } \\
\text { gösterme iznini almak. 2. Bir } \\
\text { sanatı yapmak için ustanın iznini } \\
\text { almak. 3. Kâğıt oyunlarında karşı } \\
\text { tarafın oynadığı kâğgdın daha } \\
\text { önemlisini oynayarak üstünlük }\end{array}$ & $\begin{array}{l}\text { Kir şeyi veya birini birakmak, } \\
\text { vazgeçmek (Oniani, 1966: 188). }\end{array}$ \\
\hline
\end{tabular}




\begin{tabular}{|c|c|c|c|}
\hline & $\begin{array}{l}\text { sağlamak (https://sozluk.gov.tr/ } \\
\text { 14.11.2019'da erişildi). }\end{array}$ & & \\
\hline Eline almak & $\begin{array}{l}\text { 1. Bir işin veya yerin yönetimini } \\
\text { üstlenmek. 2. Bir işi kendi } \\
\text { yapmaya } \\
\text { (https://sozluk.gov.tr/ başlamak } \\
\text { 14.11.2019'da erişildi). }\end{array}$ & Khelt igdo & $\begin{array}{l}\text { Bir şeye zorla sahip olmak } \\
\text { (Oniani, 1966: 187) }\end{array}$ \\
\hline Eline bakmak & $\begin{array}{l}\text { 1. Bir kimsenin yardımıyla } \\
\text { geçinmek. 2. Biri 'ne getirdi` } \\
\text { diye } \\
\text { (https://sozluk.gov.tr/ gözlemek } \\
\text { 14.11.2019'da erişildi). }\end{array}$ & Khelebşi qureba & $\begin{array}{l}\text { Birinden çıkar beklemek (Oniani, } \\
\text { 1966: 187) }\end{array}$ \\
\hline Eline düşmek & $\begin{array}{l}\text { 1. Egemenliği, buyruğu altına } \\
\text { girmek. 2.Yakalanmak. 3. Birine } \\
\text { muhtaç olmak. 4. Rastlamak, } \\
\text { tesadüf } \\
\text { (https://sozluk.gov.tr/ } \\
\text { 14.11.2019'da erişildi). }\end{array}$ & Khelşi çavardna & $\begin{array}{l}\text { Çok istenen bir şeyi edinmek; } \\
\text { Esir düşmek (Oniani, 1966: 193). }\end{array}$ \\
\hline Elden gitmek & $\begin{array}{l}\begin{array}{l}\text { Bir şeyi yitirmek, o } \\
\text { yoksun }\end{array} \\
\text { (https://sozluk.gov.tr/ } \\
\text { kalmak }\end{array}$ & Khelidan tszasvla & $\begin{array}{l}\text { Doğru yolunu kaybetmek, kötü } \\
\text { alışkanlıkları edinmek; Umutsuz } \\
\text { olmak (Oniani, 1966: 188). }\end{array}$ \\
\hline El koymak & $\begin{array}{l}\text { 1. Bir yolsuzluğu ortaya } \\
\text { çlkarmak, incelemek, vaziyet } \\
\text { etmek. 2. Üstüne konmak. 3. } \\
\text { Zorla almak. 4. İsisi üzerine almak, } \\
\text { sorumluluğu üstlenmek. 5. } \\
\text { Yetkili organ bir malı veya bir } \\
\text { kuruluşu kendi yönetimine } \\
\text { almak } \\
\text { (https://sozluk.gov.tr/ } \\
\text { 14.11.2019'da erişildi). }\end{array}$ & Khelis dadeba & $\begin{array}{l}\text { Birini suçlamak (Oniani, 1966: } \\
\text { 190). }\end{array}$ \\
\hline El değiştirmek & $\begin{array}{l}\text { Bir şeyin kullanımı veya } \\
\text { mülkiyeti bir kimseden başka bir } \\
\text { kimseye geçmek. } \\
\text { (https://sozluk.gov.tr/ } \\
\text { 14.11.2019'da erişildi). }\end{array}$ & $\begin{array}{l}\text { Khelis } \\
\text { monatsvleba }\end{array}$ & $\begin{array}{l}\text { Birinden yardım almak; Birinden } \\
\text { borç para almak (Oniani, 1966: } \\
\text { 191) }\end{array}$ \\
\hline El yıkamak & $\begin{array}{l}\text { İlgisini kesmek } \\
\text { (https://sozluk.gov.tr/ } \\
\text { 14.11.2019'da erişildi). }\end{array}$ & Khelis dabanva & $\begin{array}{l}\text { Sorumluluğu üstlenmemek } \\
\text { (Oniani, 1966: 189). }\end{array}$ \\
\hline
\end{tabular}

\section{Sonuc}

Deyimlerin toplumun kültürünü, yaşantısını, dünya görüşünü, hayal gücünü, gelenek ve göreneklerini yansıtan kalıplaşmış sözler oldukları söylenebilir. Bir dildeki deyimlerin çokluğu, o dilin anlatım zenginliğini göstermektedir. Bu açıdan bakıldığında gerek Türkiye Türkçesi, gerek Gürcücenin deyim varlığı bakımından çok zengin olduğu söylenebilir. Her iki dildeki bu zenginlik, organ adı olan el kelimesinin bulunduğu deyim varlı̆̆ının çokluğundan da anlaşılmaktadır.

Bu araştırmada Türkiye Türkçesinde ve Gürcücede el organ adıyla kurulmuş deyimler incelenerek anlam eşdeğerlikleri araştıılmıştır. İnceleme sırasında E. Mamulia’nın hazırlamış olduğu Türkçe-Gürcüce Deyimler Sözlüğü ve TDK’nin Atasözleri ve Deyimler Sözlüğü’nde geçen el organ adıyla kurulmuş 
deyimler temel alınmıştır. Her iki dilde anlam ve kelime tercihi bakımından aynı olan, el organ adı geçen 74 deyim tespit edilmiştir.

"El" organ adıyla kurulan deyimlerle sınırlı tutulan bu çalışmada deyimlerin \%45’i (33 adet) tam eşdeğerlik, yani hem yapısal hem de anlamsal bakımından birebir benzerlik göstermiştir. $\mathrm{Bu}$ değerlendirmeye göre deyimlerin \%32'si (24 adet) en az bir kelimesi ortak ve anlam bakımından aynı olan yani kısmî eşdeğerlik grubuna giren deyimlerdir. \%12'si (9 adet) ise sıfır eşdeğerlik grubunda değerlendirilmiştir. Deyimlerin \%11'lik kısmı anlam bakımından farklı, kelime seçimi bakımından aynı olan yani yalancı eşdeğerlik barındıran deyimlerden oluşmaktadır. Söz konusu deyimler eş anlamlı unsurlardan oluşmuş ancak kavram alanı farklı olan deyimlerdir.

Gürcüce ve Türkçe dil ilişkileri üzerine yazılmış fazla sayıda makale ve monografik araştırma bulunmaktadır. Gürcistan'da Türkoloji üzerine çalışan çok sayıda uzman olmasına rağmen Türkçe ve Gürcüce dil ilişkilerinde çözülemeyen oldukça çok konu olduğunu belitmek gerekir. Bu nedenle, bu tür çalışmalarının önemi büyüktür ve aynı zamanda Türkçe-Gürcüce konusunda çok az sayıda bulunan Türkçe yazılmış kaynaklara bir katkı sağlanması da umut edilmektedir.

Sonuç olarak şunu belirtmeliyiz ki ortak deyimler üzerine şimdiye kadar pek çok araştırma yapılmış olmasına rağmen iki kadim kültürün deyim varlığının zenginliği, konunun daha detaylı incelenmesi gereğini ortaya çıarmaktadır. Dilbilim alanındaki son gelişmeler göz önüne alınarak deyimlerin çeşitli açılardan incelenmesi ilgi çekici sonuçların elde edilmesine imkan sağlayacaktır.

\section{Kaynakça}

Aksoy, Ö. A. (2014). Atasözleri ve Deyimler Sözlüğü 1.(7. Baskı), Ankara : İnkılap.

Aktaş, A. (2008). Karşılaştırmalı Dilbilim Açısından Türkçe ve Almanca Deyimlerde Kadın, Bir Bilim Kategorisi olarak "KADIN" Uluslararası Sempozyumu Bildiri Kitabı içinde (ss. 31-37). Eskişehir : Anadolu Üniversitesi

Kenzhalin, K. (2017), Türk Dünyasında Deyim Bilimi Çalışmaları, Türk Dünyası Dergisi, 43 sayı, s. 107124, Ankara.

Korkmaz, Z. (1992), Gramer Terimleri Sözlüğ̈̈. Ankara : TDK.

Mamulia, E. (2006), Türkçe-Gürcüce Deyimler Sözlüğü. Tiflis : Tsartqela.

Oniani, A. (1966), Kartuli İdiomebi. Tiflis : Nakaduli.

Öztürk, G. M. (2019). Kültür Aktarımında Çeviri Stratejileri: Mikheil Cavahişvili’nin "Çançura" Adlı Öyküsünün Türkçe Çevirisindeki Deyimlerin Karşlaştırmalı Analizi, Uluslararası Türkçe Edebiyat Kültür Ĕ̆itim Dergisi Sayı: 8/3, s. 1630-1647.

Şahin, A. B. (2019), Hayvan İsimleri ile Kurulmuş Türk ve Gürcü Atasözlerinde Eşdeğerlikler, Turkish Studies - Language and Literature Volume 14 Issue 2, s. 879-890.

Tandilava, L., Tsetskhladze, N. (2015), Gürcüce-Türkçe Deyimlerin Variyantlara Göre Kültürel Dialoglar, Kültür Evreni, 26 sayı, s. 102-107.

Taqaişvili, A. (1961), Kartuli Prazeologiis Sakitkhebi. Tiflis : Gürcistan SSCB Bilimler Akademisi.

Türk Dil Kurumu, Atasözleri ve Deyimler Sözlüğü (https://sozluk.gov.tr/ 14.11.2019'da erişildi).

Uğurlu, M. (2012), “Türk Lehçeleri Arasında Benzer Kelimelerin Eş Değerlik Durumu”, Turkish Studies 7/4, s. 215-222.

Vardar, B. (2002), Açıklamalı Dilbilim Terimleri Sözlüğ̈̈ü, İstanbul : Multilingual. 